Mini-review

\title{
Overflow movements and white matter abnormalities in ADHD
}

\author{
Elisa D'Agati, Livia Casarelli, Maria Bernarda Pitzianti, Augusto Pasini * \\ Unit of Child Neurology and Psychiatry, Department of Neuroscience, University of Rome "Tor Vergata”, Italy
}

\section{A R T I C L E I N F O}

\section{Article history:}

Received 22 September 2009

Received in revised form 9 January 2010

Accepted 18 January 2010

Available online 25 January 2010

\section{Keywords:}

ADHD

MPH

Myelination

Overflow movements

White matter

\begin{abstract}
A B S T R A C T
Multiple motor abnormalities have been identified in some children with Attention Deficit/Hyperactivity Disorder (ADHD). These include persistence of overflow movements, impaired timing of motor responses and deficits in fine motor abilities. Motor overflow is defined as co-movement of body parts not specifically needed to efficiently complete a task. The presence of age-inappropriate overflow may reflect immaturity of the cortical systems involved in automatic motor inhibition. Theories on overflow movements consistently implicate impairments in white matter (WM) tracts, including the corpus callosum. WM connections might be altered selectively in brain networks and thus influence motor behaviours. We reviewed the scientific contributions on overflow movements and WM abnormalities in ADHD. They suggest that WM abnormalities in motor/premotor circuits, which are important for motor response inhibition, might be responsible for overflow movements in patients with ADHD.
\end{abstract}

(c) 2010 Elsevier Inc. All rights reserved.

\section{Introduction}

It has been hypothesized that Attention Deficit/Hyperactivity Disorder (ADHD) is due to structural defects in the brain networks that influence cognitive, affective and motor behaviours (Makris et al., 2008). In addition to the main symptoms of inattention, impulsiveness and hyperactivity, neurological soft signs (NSS) are often associated with ADHD (Pasini and D'Agati, 2009). NSS are discrete motor and sensory disorders that cannot be linked to specific cerebral lesions (Shafer et al., 1983). The Physical and Neurological Examination for Subtle Signs (PANESS, Denckla, 1985) is the most used scale for determining whether or not NSS are present. It investigates the following areas: Gaits and Stations, Overflow, Dysrythmia, and Timed Movements (Denckla, 1985). Careful assessment of children's basic motor functions can reveal soft motor deficits. Neurological soft signs include overflow movements, involuntary movements, and dysrhythmia. Motor overflow is defined as

Abbreviations: ADHD, Attention Deficit/Hyperactivity Disorder; NSS, Neurological soft signs; WM, white matter; CC, corpus callosum; DSM, Diagnostic and Statistical Manual of Mental Disorders; IQ intelligence quotient; NESS, Neurological Examination for Subtle Signs; SMA, supplementary motor area; Pre-SMA, pre-supplementary motor area; fMRI, functional magnetic resonance imaging; DWM, deep white matter; MRI, magnetic resonance imaging; DTI, Diffusion tensor imaging; FA, fractional anisotropy; DA, dopamine; MPH, methylphenidate; TMS, transcranial magnetic stimulation.

* Corresponding author. Unit of Child Neurology and Psychiatry, Department of Neuroscience, University of Rome "Tor Vergata", Via Alberico 2 n.35, 00193 Rome, Italy. Tel.: +3906 42013020; fax: +390641400343.

E-mail addresses: elisadagati@gmail.com (E. D'Agati), liviacasarelli@hotmail.com (L. Casarelli), tempilunghi@libero.it (M.B. Pitzianti), pasini@uniroma2.it (A. Pasini). co-movement of body parts not specifically needed to efficiently complete a task (Larson et al., 2007). There are a number of different forms of motor overflow: associated movement, contralateral motor irradiation and mirror movement. Associated movement refers to involuntary movement in non-homologous muscles, either contralaterally or ipsilaterally (Abercrombie et al., 1964), while contralateral motor irradiation and mirror movements are the involuntary movements which occur in the homologous muscles contralateral to voluntary movements (Armatas et al., 1994).

Some individuals in the general population exhibit overflow movements naturally. These include children under the age of 10 , elderly subjects and those suffering from certain neurological/psychiatric disorders (Cohen et al., 1967). The ability to inhibit unnecessary movements develops slowly over time. Nevertheless, the persistence of soft signs into later childhood and adolescence suggests motor dysfunction and is associated with atypical neurological development (Mostofsky et al., 2003). The age at which NSS are expected to be absent or are considered pathological has not been established. However, the steady decline of these signs in subsequent neurological examinations indicates the progressive maturity of the nervous system (Martins et al., 2008). It has been documented that motor overflow is present in normal children up to age nine and that it systematically diminishes from about age 10 (Cohen et al., 1967). A common explanation for these observations on overflow is that children do not have a fully myelinated nervous system until that age (Reitz and Muller, 1998). Theories on overflow movements consistently implicate impairment in white matter (WM) tracts, including, in particular, the corpus callosum (CC) (Dennis, 1976). In any case, this tract is still undergoing considerable maturation prior to age 10 (Nass, 1985). A study on older children 
suggests that the directionality of diffusion in WM pathways continues to increase from childhood through adolescence (Barnea-Goraly et al., 2005). In this paper, we reviewed scientific contributions on the pathogenesis of motor overflow in ADHD.

\section{Overflow movements in ADHD}

Multiple abnormalities of the motor system have been identified in some drug-naive children with ADHD. These include persistence of overflow movements (Denckla and Rudel, 1978), impaired timing of motor responses (Rubia et al., 2003) and deficits in fine motor abilities (Pitcher et al., 2003).

Prior to the era of DSM diagnosis of ADHD, the presence of excessive overflow movements was reported in studies that included children with symptoms of hyperactivity and inattentiveness. For example, Denckla and Rudel (1978) used coordination tests to compare 48 hyperactive boys (with normal IQ and no learning disabilities) with 50 control boys. The Authors found that overflow movements differentiated hyperactive boys from healthy subjects at all ages (Denckla and Rudel, 1978). Waber et al. (1985) extended this concept using epidemiological school-based research and showed that the presence of overflow movements was correlated with inadequate attentiveness in school-age children (Waber et al., 1985). Subsequently, Lazarus and Todor (1991) studied the effects of attentional processes in regulating associated movement in 50 male children. These findings supported the view that the integration of higher order processes, such as attention, with lower-level neuromotor inhibitory mechanisms plays a role in the reduction of associated movement with increasing age (Lazarus and Todor, 1991). Mostofsky et al. (2003) showed that children with ADHD had significantly more overflow movements than controls and made more errors on the conflicting and contralateral motor response tests, compared to control subjects. They found positive correlations between measures of overflow movements and measures of response inhibition, which supports the hypotheses that age-inappropriate overflow reflects immaturity of the cortical systems involved in automatic inhibition (Mostofsky et al., 2003). Uslu et al. (2007) underlined that certain factors investigated by the Neurological Examination for Subtle Signs (NESS), such as speed of movement, dysrhythmia and overflow with timed movements, provide important information that could increase our understanding of the neurobiological bases of ADHD and the clinical implications of NSS. They studied a group of 30 children with ADHD using the NESS and found an increase in overflow movements in children with ADHD (Uslu et al., 2007). Persistence of overflow into late childhood and adolescence (which is often seen in children with ADHD) suggests a neurodevelopmental lag in the systems that support the inhibition of overflow (Mostofsky et al., 2003).

\subsection{Cortical origin of motor overflow in $A D H D$}

Overflow movements likely reflect dysfunction within motor and premotor circuits that are important for the execution and preparation of motor responses (Leinsinger et al., 1997; Mayston et al., 1999; Cincotta et al., 2002). In a functional magnetic resonance imaging (fMRI) study, Mostofsky et al., 2006 found a smaller extent of activation in the contralateral primary motor cortex in ADHD during performing a simple motor task (Mostofsky et al., 2006). This finding might help to explain why children with ADHD generally demonstrate greater mirror overflow movements than do their typically developing peers (Mostofsky et al., 2003). A smaller extent of activation in the contralateral primary motor cortex could represent insufficient recruitment of neuronal activity necessary to mobilize transcallosal interhemispheric inhibition (Mostofsky et al., 2006).

The neural mechanisms underlying habituated motor responding and motor response inhibition in children with ADHD, were studied by comparing fMRI activation during a Go/No go task in 25 children with ADHD and 25 typically developing children, aged 8-13 years. The
Authors found a functional anomaly of the pre-SMA in ADHD (Suskauer et al., 2008). The striatal projections from the pre-SMA largely extend to the caudate nucleus and the middle and rostral putamen (Lehericy et al., 2004). Individuals with ADHD showed excessive overflow movements on motor examination (Denckla and Rudel, 1978), and deficits on motor response inhibition tasks (Shue and Douglas, 1992; Mostofsky et al., 2001). These findings point to abnormalities in circuits originating in motor (supplementary motor area, SMA) and premotor (Pre-SMA) areas (Mostofsky et al., 2002). Deficits in motor response inhibition in ADHD can be attributed to SMA/premotor (overflow movements; deficits in motor response inhibition) circuits. The presence of involuntary movements in untreated ADHD patients may be due to dysfunction of motor/caudal premotor circuits.

The above-mentioned centres process the information conveyed to them by their WM fiber connections: thus, any WM abnormalities in these circuits interfere with their functions. In particular the myelination of the CC allows for more rapid conduction of nerve impulses and isolates axons from each other to prevent unwanted interference, enabling more efficient interhemispheric transfer (Mayston et al., 1999). Therefore, as age and myelination increase, the CC may commence effective mediation of interhemispheric transfer, either in terms of increase inhibition or reduced facilitation, thus dampening overflow. Conversely, in the elderly the process of naturally occurring callosal agenesis (including a decrease in size of the CC and demyelination of callosal fibers) is thought to lead to inefficient transcallosal functioning (Nass, 1985). Clarify the cortical origins of motor overflow in ADHD subjects could lead to a greater understanding of some brain abnormalities in these patients. For example, research into ADHD has indicated that motor anomalies are present before the onset of the clinical symptoms (Rasmussen and Gillberg, 2000). Such finding supports the hypothesis on developmental origins of brain abnormalities in ADHD.

\section{WM abnormalities in ADHD}

Neuroimaging studies report reduced WM volumes (Castellanos et al., 2002), midsagittal CC areas (Krain and Castellanos, 2006), and cortical thickness (Castellanos et al., 2002) in ADHD patients compared with controls. One of the most replicated alterations is a significantly smaller $\mathrm{CC}$, and there are conflicting reports regarding the affected callosal segments (Luders et al., 2009). Moreover, recent magnetic resonance imaging (MRI) structural investigations show that WM alterations are present in children, adolescents and adults with ADHD (Makris et al., 2008). Table 1 presents an overview of white matter abnormalities in ADHD patients from the literature. In this section, we discuss WM abnormalities in motor/premotor circuits because of their importance in the pathogenesis of overflow movements.

Anatomic imaging studies of children with ADHD reported localized anomalies in pre-SMA area, including reduced volume and reduced of the deep white matter (DWM) volume (Mostofsky et al., 2002) and thickness when compared with control children (Shaw et al., 2006). The definition of DWM allowed a distinction between short association fibers (gyral white matter) and long or projecting association fibers DWM (Makris et al., 1999). The volume reductions in the pre-SMA appear to be preferentially due to decreases in their white matter components, suggesting a primarily axonal abnormality in the ADHD group (Ranta et al., 2009).

Diffusion tensor imaging (DTI) is an MRI modality that provides information about the direction and integrity of neural fiber tracks in the brain in vivo. DTI for evaluating the organization and coherence of WM fiber tracts has also been used extensively to estimate WM abnormalities in psychiatric patients (Zou et al., 2008). From DTI data one can compute fractional anisotropy (FA), which is a measure of the directionality of water diffusion through tissue (Basser et al. 1994). FA 
Table 1

Overview of white matter abnormalities in ADHD patients from literature.

\begin{tabular}{|c|c|c|c|c|c|}
\hline Studies & Number patients & Sex & Mean age (years) & Neuroimaging technique & Results \\
\hline Pavuluri et al. (2009) & 13 & $\mathrm{M} / \mathrm{F}$ & 13.4 & DTI & Decreased FA in anterior corona radiata \\
\hline Silk et al. (2009) & 15 & M & 13 & DTI & $\begin{array}{l}\text { Left fronto-temporal regions and right } \\
\text { parietal-occipital regions }\end{array}$ \\
\hline Hamilton et al. (2008) & 17 & $\mathrm{M} / \mathrm{F}$ & 11.96 & DTI & $\begin{array}{l}\text { Reduced FA in the corticospinal tract and the } \\
\text { superior longitudinal fasciculus }\end{array}$ \\
\hline Makris et al. (2008) & 12 & $\mathrm{M} / \mathrm{F}$ & $\begin{array}{l}\text { Adults with } \\
\text { childhood ADHD }\end{array}$ & DTI & $\begin{array}{l}\text { FA significantly smaller in cingulum bundle and superior } \\
\text { longitudinal fascicle II in the right hemisphere }\end{array}$ \\
\hline Casey et al. (2007) & 40 & $\mathrm{M} / \mathrm{F}$ & 48.35 & fMRI & Atypical development and regularity of frontostriatal tracts \\
\hline McAlonan et al. (2007) & 28 & M & 9.5 & Voxel-based MRI & $\begin{array}{l}\text { Smaller white matter volume in ADHD was distributed } \\
\text { bilaterally in frontal, temporal and parietal lobes }\end{array}$ \\
\hline Carmona et al. (2005) & 25 & $\mathrm{M} / \mathrm{F}$ & 11 & Voxel-based morphometry & $\begin{array}{l}\text { No differences in WM volume between ADHD children and } \\
\text { control subjects }\end{array}$ \\
\hline Ashtari et al. (2005) & 18 & $\mathrm{M} / \mathrm{F}$ & 8.94 & DTI & $\begin{array}{l}\text { Decreased FA in right premotor, right striatal, right cerebral } \\
\text { peduncle, left middle cerebellar peduncle, left cerebellum, } \\
\text { and left parieto-occipital areas }\end{array}$ \\
\hline Pueyo et al. (2003) & 11 & $\mathrm{M} / \mathrm{F}$ & 15,5 & fMRI & Higher degree of myelination in the right frontal region \\
\hline Kates et al. (2002) & 13 & $\mathrm{M} / \mathrm{F}$ & 9,5 & Frontal lobe morphometry & Volumetric reductions in white matter of the prefrontal cortex \\
\hline Castellanos et al. 2002 & 152 & $\mathrm{M} / \mathrm{F}$ & 11.5 & Anatomic MRI & Strikingly smaller total white matter volumes \\
\hline Overmeyer et al. (2001) & 18 & $\mathrm{M} / \mathrm{F}$ & 10.4 & Voxel-based MRI & $\begin{array}{l}\text { Central white matter deficits in the left hemisphere anterior to } \\
\text { the pyramidal tracts and superior to the basal ganglia }\end{array}$ \\
\hline Semrud-Clikeman et al. (2000) & 10 & $\mathrm{M} / \mathrm{F}$ & 12.5 & MRI-based morphometry & Smaller volume of the white matter of the right frontal lobe \\
\hline Filipek et al. (1997) & 15 & M & 12.4 & MRI-based morphometry & $\begin{array}{l}\text { Smaller volumes of right anterior-superior frontal region and } \\
\text { bilateral retrocallosal parietal-occipital region white matter }\end{array}$ \\
\hline
\end{tabular}

MRI (magnetic resonance imaging), DTI (diffusion tensor imaging), FA (fractional anisotropy), fMRI (functional magnetic resonance imaging).

values range from 0 to 1 and are higher in more organized WM fibers, where myelinated tracts restrict diffusion. DT-MRI study shows decreased FA in the right SMA in children and adolescents with ADHD (Ashtari et al., 2005) and support evidence of reduced myelination in that area. The finding of lower FA in children with ADHD is intriguing given the role of the SMA in planning, initiation, and execution of motor acts (Amador and Fried, 2004). Furthermore, the greatest reductions in glucose metabolism in adults with childhood-onset hyperactivity were found in the premotor cortex (Zametkin et al., 1990). Together, these data implicate a neurodevelopmental process that alters neural system configuration, particularly in the motor circuit in children with ADHD. WM signal intensities may also show differences that indicate abnormal cerebral myelination. The demonstration of FA abnormalities in adults who had ADHD in childhood provides further support for the persistence of structural abnormalities into adulthood (Makris et al., 2008).

\subsection{Role of WM abnormalities in the pathogenesis of overflow movements in $A D H D$}

WM is thought to enhance speed and fidelity in the transmission of information encoded in action potentials that propagate along neurons and likely contribute to age-related improvements in cognition (Marsh et al., 2008) and motor control. Myelination in the cortex proceeds in a posterior-to-anterior direction and seems to follow the maturation of functional circuits, with sensory pathways myelinating first, followed by motor pathways and, finally, by association areas (Huttenlocher, 2002). Myelination is accompanied by proliferation and differentiation of the oligodendrocytes necessary for neuronal insulation and metabolism. Evidence of the role of oligodendroglia in major mental disorders has grown significantly in the past few years. Since acute amphetamine treatment of young adults has been reported to stimulate glucose uptake in the frontal lobes, Todd and Botteron hypothesized that reduced catecholaminergic input in ADHD leads to a decrease in astrocyte-mediated neuronal energy metabolism and impaired frontal function (Todd and Botteron, 2001). Oligodendroglial abnormalities might also be due to dopamine (DA) system dysfunction (Sokolov, 2007). Some DA receptors are involved in oligodendrocyte development. Identification of the dopamine D3 receptor (D3r) has been described in immature oligodendrocytes of mouse primary glial cultures in vitro and in vivo during the period of major myelin deposition (Bongarzone et al., 1998). This finding provides evidence that D3r may modulate the timing of oligodendrocyte maturation and subsequent elaboration of myelin sheaths. Furthermore, expression of the dopamine D2 receptor (D2r) in mature oligodendrocytes (Howard et al., 1998) suggests that dopamine may have a nonsynaptic function in these cells (Bongarzone et al., 1998). When oligodendrocyte precursors divide and migrate in the brain, dopamine might act on cells as a precursor. Since oligodendrocytes reach their fully differentiated state in culture, D3r expression, which would make the fully mature oligodendrocytes refractory to the actions of dopamine (Bongarzone et al., 1998), disappears. The D3r and D2r receptors are expressed at different stages in oligodendrocyte development, because D2r expression occurs after D3r expression. D4r (as well as D2r and D3r) might also regulate the outgrowth of neuronal processes (Swarzenski et al., 1994). Therefore, in a cell whose primary function is to elaborate the myelin membrane, at least the dopamine system might modulate the cytoarchitecture of the oligodendrocyte in terms of the amount and timing of myelin formation (Bongarzone et al., 1998). Genetic variants at the $\mathrm{DRD}_{2}, \mathrm{DRD}_{3}$, or $\mathrm{DRD}_{4}$ locus might play a role in direct connections among a genotype, a neurotransmitter level of dopamine, and oligodendrocyte development. Further, impaired myelin synthesis resulting from insufficient dopamine uptake in oligodendrocytes should have a detrimental effect on the coordinated myelination of axons during development, leading to impaired communication among the brain regions and poor integration of information in these targeted brain structures. There is increased interest in ADHD as a heritable neuropsychiatric condition linked to the pathogenesis of brain dopamine (Blum et al., 2008). Our hypothesis is that WM abnormalities in motor/premotor structures, which lead to the inhibition of motor responses, might be responsible for the overflow movements in patients with ADHD (See Fig. 1).

\subsection{Role of methylphenidate on synaptic plasticity and myelination}

In children with ADHD, methylphenidate (MPH) modulates disturbed facilitatory and inhibitory motor circuits (Buchmann et al., 2007). The MPH effects on motor system excitability and motor control can be investigated in vivo by means of single- and paired- 
pulse transcranial magnetic stimulation (TMS). Several investigations using TMS showed that neural inhibitory motor circuits are disturbed in ADHD children and have provided an enhancement of inhibitory mechanisms in these brain regions after the oral intake of MPH (Moll et al., 2000; Buchmann et al., 2007). MPH treatment produces an increase in DA signaling through multiple actions, including blockade of the DA reuptake transporter, amplification of DA response duration, disinhibition of D2r and amplification of DA tone (Wilens, 2008). These effects could be important because $\mathrm{D} 2 \mathrm{r}$ receptors are expressed in oligodendrocyte development and might also regulate the outgrowth of neuronal processes. MPH also influences the transcription and synaptic plasticity regulatory proteins in specific corticostriatal circuits, and MPH treatment seems to potentiate synaptic plasticity.

Genetic regulation of synaptic plasticity is involved in MPH therapeutic effect in ADHD. Has been demonstrated that more than 700 genes were upregulated in the striatum of MPH-treated rats (Adriani et al., 2006). A group of these genes suggested active axonal myelination. They mediated survival of immature cells after contact with a newly produced axonal matrix (laminin B1, collagens, integrin alpha 6) and stabilization of myelinating glia-axon contacts (RAB13, contactins 3 and 4) (Adriani et al., 2006). Also, expression of the Homer 1 gene increased in the striatum of MPH-treated rats (Adriani et al., 2006). The Homer family of proteins is a key constituent of postsynaptic density, indeed it is a specialized structure that has recently been implicated in synaptic plasticity and in the pathophysiology of behavioral disease (Iasevoli et al., 2009).

Notably, few studies have investigated the effect of MPH on NSS. However, marked improvement or complete resolution of NSS following treatment with MPH was described (Lerer and Lerer, 1976). More research is needed to assess the sensory and motor soft signs associated with ADHD and to integrate clinical evidence with neuroimaging findings, neuropsychological dysfunction and pharmacological effects of the drugs commonly used to treat the disorder (Pasini and D'Agati, 2009).

\section{Conclusion}

Overflow movements are present in patients with ADHD and may reflect immaturity of the cortical systems involved in automatic motor inhibition (Mostofsky et al., 2003). Deficits in motor response inhibition in ADHD can be attributed to motor/premotor circuits (Mostofsky et al., 2002). The volume reductions in these areas appear to be due to decreases in their white matter components (Ranta et al., 2009), suggesting a primarily axonal abnormality in ADHD patients. The presence of motor overflow supports the hypothesis that the brain abnormalities in ADHD have a developmental origin. Oligodendroglial abnormalities might be due to the dysfunction of a DA system (Sokolov, 2007). Genetic variants of dopaminergic DRD3, DRD2 and

\section{Alterated myelination caused by dysfunction on D2r, D3r or D4r expression in olygodendrocites}

\section{WM abnormalities in motor/premotor circuits} important for motor response inhibition

\section{OVERFLOWMOVEMENTS}

Fig. 1. Here is schematized the possible alteration at the base of overflow movements in patients with ADHD.
DRD4 genes might be responsible for the altered expression of these dopamine receptors, which are important for oligodendrocyte development. Marked improvement or complete resolution of NSS following treatment with methylphenidate (MPH) was described in patients with ADHD (Lerer and Lerer, 1976). MPH treatment produces an increase in DA signaling through multiple actions, including blockade of the DA reuptake transporter and disinhibition of D2r (Wilens, 2008). Genetic regulation of synaptic plasticity has a role in MPH therapeutic effect in ADHD. It was demonstrated that more than 700 genes were upregulated in the striatum of MPH-treated rats (Adriani et al., 2006). A group of these genes suggested active axonal myelination.

In this review article, we propose that WM abnormalities in motor/ premotor circuits are responsible for the persistence of overflow movements in patients with ADHD. The effect of MPH on myelin/ oligodendrocyte-related genes in a mature oligodendrocyte explains the improvement or resolution of overflow movements in children with ADHD.

\section{References}

Abercrombie ML, Lindon RL, Tyson MC. Associated movements in normal and physically handicapped children. Dev Med Child Neurol 1964;6:573-80.

Adriani W, Leo D, Guarino M, Natoli A, Di Consiglio E, De Angelis G, et al. Short-term effects of adolescent methylphenidate exposure on brain striatal gene expression and sexual/endocrine parameters in male rats. Ann N Y Acad Sci 2006;1074:52-73.

Amador N, Fried I. Single-neuron activity in the human supplementary motor area underlying preparation for action. J Neurosurg 2004;100:250-9.

Armatas CA, Summers JJ, Bradshaw JL. Mirror movements in normal adult subjects. J Clin Exp Neuropsychol 1994;16:405-13.

Ashtari M, Kumra S, Bhaskar SL, Clarke T, Thaden E, Cervellione KL, et al. Attention-deficit/ hyperactivity disorder: a preliminary diffusion tensor imaging study. Biol Psychiatry 2005;57:448-55.

Barnea-Goraly N, Menon V, Eckert M, Tamm L, Bammer R, Karchemskiy A, et al. White matter development during childhood and adolescence: a cross-sectional diffusion tensor imaging study. Cereb Cortex 2005; 15:1848-54.

Basser PJ, Mattiello J, LeBihan D. MR diffusion tensor spectroscopy and imaging. Biophys J 1994;66:259-67.

Blum K, Chen AL, Braverman ER, Comings DE, Chen TJ, Arcuri V, et al. Attention-deficithyperactivity disorder and reward deficiency syndrome. Neuropsychiatr Dis Treat 2008;4:893-918.

Bongarzone ER, Howard SG, Schonmann V, Campagnoni AT. Identification of the dopamine D3 receptor in oligodendrocyte precursors: potential role in regulating differentiation and myelin formation. J Neurosci 1998;18:5344-53.

Buchmann J, Gierow W, Weber S, Hoeppner J, Klauer T, Benecke R, et al. Restoration of disturbed intracortical motor inhibition and facilitation in attention deficit hyperactivity disorder children by methylphenidate. Biol Psychiatry 2007;62: 963-9.

Carmona S, Vilarroya O, Bielsa A, Tremols V, Soliva JC, Rovira M, et al. Global and regional grey matter reductions in ADHD: a voxel-based morphometric study. Neurosci Lett 2005;389:88-93.

Casey BJ, Epstein JN, Buhle J, Liston C, Davidson MC, Tonev ST, et al. Frontostriatal connectivity and its role in cognitive control in parent-child dyads with ADHD. Am J Psychiatry 2007;164:1729-36.

Castellanos FX, Lee PP, Sharp W, Jeffries NO, Greenstein DK, Clasen LS, et al Developmental trajectories of brain volume abnormalities in children and adolescents with attention-deficit/hyperactivity disorder. JAMA 2002;288:1740-8.

Cincotta M, Borgheresi A, Boffi P, Vigliano P, Ragazzoni A, Zaccara G, et al. Bilateral motor cortex output with intended unimanual contraction in congenital mirror movements. Neurology 2002;58:1290-3.

Cohen HJ, Taft LT, Mahadeviah MS, Birch HG. Developmental changes in overflow in normal and aberrantly functioning children. J Pediatr 1967;71:39-47.

Denckla MB. Revised neurological examination for subtle signs (1985). Psychopharmacol Bull 1985;21:773-800.

Denckla MB, Rudel RG. Anomalies of motor development in hyperactive boys. Ann Neurol 1978;3:231-3.

Dennis M. Impaired sensory and motor differentiation with corpus callosum agenesis: a lack of callosal inhibition during ontogeny? Neuropsychologia 1976;14:455-69.

Filipek PA, Semrud-Clikeman M, Steingard RJ, Renshaw PF, Kennedy DN, Biederman J. Volumetric MRI analysis comparing subjects having attention-deficit hyperactivity disorder with normal controls. Neurology 1997;48:589-601.

Hamilton LS, Levitt JG, O'Neill J, Alger JR, Luders E, Phillips OR, et al. Reduced white matter integrity in attention-deficit hyperactivity disorder. Neuroreport 2008;19: 1705-8.

Howard S, Landry C, Fisher R, Bezouglaia O, Handley V, Campagnoni A. Postnatal localization and morphogenesis of cells expressing the dopaminergic D2 receptor gene in rat brain: expression in non-neuronal cells. J Comp Neurol 1998;391: 87-98.

Huttenlocher PR. Neural Plasticity: The Effects of the Environment on the Development of the Cerebral Cortex. H. U. Press; 2002. 
lasevoli F Tomasetti C Ambesi-Impiombato A Muscettola G de Bartolomeis A Dopamine receptor subtypes contribution to Homer1a induction: insights into antipsychotic molecular action. Prog Neuropsychopharmacol Biol Psychiatry 2009;33:813-21.

Kates WR, Frederikse M, Mostofsky SH, Folley BS, Cooper K, Mazur-Hopkins P, et al. MR parcellation of the frontal lobe in boys with attention deficit hyperactivity disorder or Tourette syndrome. Psychiatry Res 2002;116:63-81.

Krain AL, Castellanos FX. Brain development and ADHD. Clin Psychol Rev 2006;26: 433-44.

Larson JC, Mostofsky SH, Goldberg MC, Cutting LE, Denckla MB, Mahone EM. Effects of gender and age on motor exam in typically developing children. Dev Neuropsycho 2007;32:543-62.

Lazarus JA, Todor JI. The role of attention in the regulation of associated movement in children. Dev Med Child Neurol 1991;33:32-9.

Lehericy S, Ducros M, Krainik A, Francois C, Van de Moortele PF, Ugurbil K, et al. 3-D diffusion tensor axonal tracking shows distinct SMA and pre-SMA projections to the human striatum. Cereb Cortex 2004;14:1302-9.

Leinsinger GL, Heiss DT, Jassoy AG, Pfluger T, Hahn K, Danek A. Persistent mirror movements: functional MR imaging of the hand motor cortex. Radiology 1997;203: 545-52.

Lerer RJ, Lerer MP. The effects of methylphenidate on the soft neurological signs of hyperactive children. Pediatrics 1976:57:521-5.

Luders E, Narr KL, Hamilton LS, Phillips OR, Thompson PM, Valle JS, et al. Decreased callosal thickness in attention-deficit/hyperactivity disorder. Biol Psychiatry 2009;65:84-8.

Makris N, Buka SL, Biederman J, Papadimitriou GM, Hodge SM, Valera EM, et al. Attention and executive systems abnormalities in adults with childhood ADHD: A DT-MRI study of connections. Cereb Cortex 2008;18:1210-20.

Makris N, Meyer JW, Bates JF, Yeterian EH, Kennedy DN, Caviness VS. MRI-base topographic parcellation of human cerebral white matter and nuclei II. Rationale and applications with systematics of cerebral connectivity. Neuroimage 1999;9: $18-45$.

Marsh R, Gerber AJ, Peterson BS. Neuroimaging studies of normal brain development and their relevance for understanding childhood neuropsychiatric disorders. J Am Acad Child Adolesc Psychiatry 2008;47:1233-51.

Martins I, Lauterbach M, Slade P, Luis H, DeRouen T, Martin M, et al. A longitudinal study of neurological soft signs from late childhood into early adulthood. Dev Med Child Neurol 2008;50:602-7.

Mayston MJ, Harrison LM, Stephens JA. A neurophysiological study of mirror movements in adults and children. Ann Neurol 1999;45:583-94.

McAlonan GM, Cheung V, Cheung C, Chua SE, Murphy DG, Suckling J, et al. Mapping brain structure in attention deficit-hyperactivity disorder: a voxel-based MRI study of regional grey and white matter volume. Psychiatry Res 2007;154:171-80.

Moll GH, Heinrich H, Trott G, Wirth S, Rothenberger A. Deficient intracortical inhibition in drug-naive children with attention-deficit hyperactivity disorder is enhanced by methylphenidate. Neurosci Lett 2000;284:121-5.

Mostofsky SH, Cooper KL, Kates WR, Denckla MB, Kaufmann WE. Smaller prefrontal and premotor volumes in boys with attention-deficit/hyperactivity disorder. Biol Psychiatry 2002;52:785-94.

Mostofsky SH, Lasker AG, Cutting LE, Denckla MB, Zee DS. Oculomotor abnormalities in attention deficit hyperactivity disorder: a preliminary study. Neurology 2001;57: 423-30.

Mostofsky SH, Newschaffer CJ, Denckla MB. Overflow movements predict impaired response inhibition in children with ADHD. Percept Mot Skills 2003:97:1315-31.

Mostofsky SH, Rimrodt SL, Schafer JG, Boyce A, Goldberg MC, Pekar JJ, et al. Atypical motor and sensory cortex activation in attention-deficit/hyperactivity disorder: a functional magnetic resonance imaging study of simple sequential finger tapping. Biol Psychiatry 2006;59:48-56.

Nass R. Mirror movement asymmetries in congenital hemiparesis: the inhibition hypothesis revisited. Neurology 1985:35:1059-62.
Overmeyer S, Bullmore ET, Suckling J, Simmons A, Simmons SC, Santosh PJ, et al. Distributed grey and white matter deficits in hyperkinetic disorder. MRI evidence for anatomical abnormality in an attention network. Psychol Med 2001;31:1425-35.

Pasini A, D'Agati E. Pathophysiology of NSS in ADHD. World J Biol Psychiatry 2009;10 (4 Pt 2):495-502.

Pavuluri MN, Yang S, Kamineni K, Passarotti AM, Srinivasan G, Harral EM, et al. Diffusion tensor imaging study of white matter fiber tracts in pediatric bipolar disorder and attention-deficit/hyperactivity disorder. Biol Psychiatry 2009;65(7):586-93.

Pitcher TM, Piek JP, Hay DA. Fine and gross motor ability in males with ADHD. Dev Med Child Neurol 2003;45:525-35

Pueyo R, Maneru C, Junque C, Vendrell P, Pujol J, Mataro M, et al. Quantitative signal intensity measures on magnetic resonance imaging in attention-deficit hyperactivity disorder. Cogn Behav Neurol 2003;16:75-81.

Ranta ME, Crocetti D, Clauss JA, Kraut MA, Mostofsky SH, Kaufmann WE. Manual MRI parcellation of the frontal lobe. Psychiatry Res 2009;172:147-54.

Rasmussen P, Gillberg C. Natural outcome of ADHD with developmental coordination disorder at age 22 years: a controlled, longitudinal, community-based study. J Am Acad Child Adolesc Psychiatry 2000;39:1424-31.

Reitz M, Muller K. Differences between 'congenital mirror movements' and 'associated movements' in normal children: a neurophysiological case study. Neurosci Lett 1998;256:69-72.

Rubia K, Noorloos J, Smith A, Gunning B, Sergeant J. Motor timing deficits in community and clinical boys with hyperactive behavior: the effect of methylphenidate on motor timing. J Abnorm Child Psychol 2003;31:301-13.

Semrud-Clikeman M, Steingard RJ, Filipek P, Biederman J, Bekken K, Renshaw PF. Using MRI to examine brain-behavior relationships in males with attention deficit disorder with hyperactivity. J Am Acad Child Adolesc Psychiatry 2000;39:477-84.

Hard thoughts on neurological soft signs. Dev Neuropsychol 1983:133-43.

Shaw P, Lerch J, Greenstein D, Sharp W, Clasen L, Evans A, et al. Longitudinal mapping of cortical thickness and clinical outcome in children and adolescents with attentiondeficit/hyperactivity disorder. Arch Gen Psychiatry 2006;63:540-9.

Shue KL, Douglas VI. Attention deficit hyperactivity disorder and the frontal lobe syndrome. Brain Cogn 1992;20:104-24.

Silk TJ, Vance A, Rinehart N, Bradshaw JL, Cunnington R. White-matter abnormalities in attention deficit hyperactivity disorder: a diffusion tensor imaging study. Hum Brain Mapp 2009;30(9):2757-65.

Sokolov BP. Oligodendroglial abnormalities in schizophrenia, mood disorders and substance abuse. Comorbidity, shared traits, or molecular phenocopies? Int J Neuropsychopharmacol 2007;10:547-55.

Suskauer SJ, Simmonds DJ, Caffo BS, Denckla MB, Pekar JJ, Mostofsky SH. fMRI of intrasubject variability in ADHD: anomalous premotor activity with prefrontal compensation. J Am Acad Child Adolesc Psychiatry 2008;8:21.

Swarzenski BC, Tang L, Oh YJ, O'Malley KL, Todd RD. Morphogenic potentials of D2, D3, and D4 dopamine receptors revealed in transfected neuronal cell lines. Proc Natl Acad Sci U S A 1994;91:649-53.

Todd RD, Botteron KN. Is attention-deficit/hyperactivity disorder an energy deficiency syndrome? Biol Psychiatry 2001;50:151-8.

Uslu R, Kapci EG, Oztop D. Neurological soft signs in comorbid learning and attention deficit hyperactivity disorders. Turk J Pediatr 2007;49:263-9.

Waber DP, Mann MB, Merola J. Motor overflow and attentional processes in normal school-age children. Dev Med Child Neurol 1985;27:491-7.

Wilens TE. Effects of methylphenidate on the catecholaminergic system in attentiondeficit/hyperactivity disorder. J Clin Psychopharmacol 2008;28:S46-53.

Zametkin AJ, Nordahl TE, Gross M, King AC, Semple WE, Rumsey J, et al. Cerebral glucose metabolism in adults with hyperactivity of childhood onset. N Engl J Med 1990;323: 1361-6.

Zou K, Huang X, Li T, Gong Q Li Z, Ou-yang L, et al. Alterations of white matter integrity in adults with major depressive disorder: a magnetic resonance imaging study.JPsychiatry Neurosci 2008;33:525-30 